\title{
Closed-Loop Bandwidth Impact on MVSA for Rotor Broken Bar Diagnosis in IRFOC Double Squirrel Cage Induction Motor Drives
}

\author{
Y. Gritli ****, A. O. Di Tommaso **, R. Miceli **, F. Filippetti *, and C. Rossi * \\ * University of Bologna, (Italy) \\ Dipartimento di Ingegneria dell'Energia Elettrica e dell'Informazione «Guglielmo Marconi». \\ E-mail: yasser.gritli@unibo.it, fiorenzo.filippetti@unibo.it, claudio.rossi@unibo.it. \\ ** University of Palermo, (Italy) \\ Department of Electrical, Electronic and Telecommunication Engineering, \\ Chemical Technologies, Automatics and Mathematical Models. \\ E-mails: ditommaso@dieet.unipa.it,rosario.miceli@unipa.it. \\ *** University of Tunis El Manar, (Tunisia) \\ LARA-Department of Electrical Engineering, National Engineering School of Tunis. \\ E-mail: yasser.gritli@esti.rnu.tn.
}

\begin{abstract}
This paper investigates the detectability of rotor broken bars in indirect rotor flux oriented control (IRFOC) for variable speed double cage induction motor drives, using vibration signature analysis techniques. The Impact of the closed loop control system cannot be neglected when the detection of rotor asymmetries in the machine is based on the signature analysis of electrical or mechanical variables. Therefore, the investigation of rotor fault components for different bandwidths of closed-loop regulators is necessary to evaluate its relevance in the above listed variables. This paper investigates the impact of the control system on relevance of the fault components computed from axial and radial vibration signals. Experimental results show the validity of this impact, and more specifically, the bandwidth PI regulators. Due to its relevance, axial vibration analysis shows a more robust fault signature, under the control impact, in separating healthy from rotor bar breakage in double squirrel cage induction motors.
\end{abstract}

Index Terms-- AC Machine; Condition monitoring; double cage rotor; rotor broken bar; induction motor drives.

\section{INTRODUCTION}

In the last few years, new diagnostic procedures have been investigated mainly focusing on renewable energy sources and power conversion issues. Improving the power conversion efficiency has quickly become the key target even if contrasting with system performances. New challenges arise thus pressing both academic and industrial research towards innovative solutions [1-7]. Efficient energy consumption is a key factor to Europe's ambitious goals for sustainable development and activities related to air pollution and climate shifting. In order to tackle the increasing electricity demand, a number of solutions for efficient energy consumption, generation of energy from renewable sources, and new power distribution business models for active energy control have been considered.
Fuel cell - based hybrid power supply systems for household appliances are actually widely investigated. Sophisticated control algorithms are usually implemented to meet hydrogen saving and efficiency requirements. Great advantages on system fault detection, prevention and recovery are brought by accurate system modelling, including the energy source itself [8-10]. Key benefits are brought by accurate measurements set up and methods [11] Since photovoltaic (PV) installed power increases all over the world, solar technology is now strongly present in the electricity market, and it cannot be seen only as a vision of the future. PV generation systems are actually available in different power sizes covering the range from domestic applications to large power generation plants [12-14].

Many different improvements have been proposed and experimented to enhance efficiency not only in energy conversion (PV fields) but also in energy management (power converters). In recent times, multi-level inverters such as $\mathrm{H}$ bridge multi-cell cascaded inverter, Neutral Point Clamped (NPC) and Active Point Clamped (APC) have also been used for a more efficient and effective PV power conversion [15-16]. Many inverter topologies have been patented, within the market development, to solve some common problems of the PV plants such as leakage currents due to parasitic capacitance of the panel and efficiency losses due to the transfer of reactive energy between the grid filters and the DC bus capacitor. Moreover, some particular topologies have been conceived of for the fault tolerant operation of PV plant. In renewable energy sources state of the art an important role is now played from sea electric energies generators, between one of the most interesting is the direct generation with a tubular linear generator.

In the last five years, the number of operating machines is estimated to 16.1 billion in 2011, with growth of about $50 \%$ [17]. Nowadays, the number of electrical machines integrated in closed-loop drives has gained ground within 
most industrial areas. Investigations on different failure modes in induction motors have revealed that $19 \%$ of the overall motor faults are related to the rotor part [18,19]. A detailed analysis of this category of faults can be found in [20]. Double cage rotors are characterized by its large outer (starting) bar resistance and large inner (running) bar leakage inductance. Since double cage motors are used for loaded startups, the outer cage must handle the large starting current for the long acceleration time, with limited path for heat dissipation [21]. Cyclic electromagnetic forces, thermal stress, environmental stress, and mechanical stress associated with the large starting current, make the outer cage more vulnerable to fatigue failure. Different techniques are used to provide accurate non-invasive on-line condition monitoring of induction motors. Instead of stator current, mechanical or electrical quantities were used as reference signal to detect the presence of rotor faults. A new technique is presented in [22], where the electromagnetic torque magnitude is computed in different ways as a function of rotor position, to detect the presence of rotor faults.

References [23] and [24] are devoted to detection of broken bars by external magnetic field analysis. Motor vibration signature analysis (MVSA) was investigated in [25], showing the effectiveness of this technique in diagnosing rotor broken bars in line-connected motors. In order to discern cases in which the presence of inter bars currents decrease the sensitivity of the motor current signature analysis (MCSA), motor axial vibration signature analysis (MAVSA) and motor radial vibration signature analysis (MRVSA) were investigated in $[25,26]$. Recently, this issue was investigated for line-fed double cage motors, operating under steady-state conditions in [26] and more recently in [27,28]. On the other hand, the rotor current mainly flows in the symmetric inner cage under steady state operating condition, and fault signature is insensitive to outer cage damage. A combined use of current and vibration analysis was developed, by correlating the signal spectra to enhance broken bars detection ability under loaded and unloaded operating conditions of the motor in [29]. It should be noted that for the above listed contributions, referred to the detection of broken bars based on vibration signature analysis, the applications are considered for line-connected motors. On the other hand, it was shown that in closed loop drives the control itself affects the behavior of electrical variables and so new diagnostic procedures are necessary for machine monitoring. More specifically, the tuning of the speed and current controllers used in closed-loop drives has a considerable impact, which can compensate the oscillations induced on the different variables in presence of rotor fault conditions [28-36]. Modulated signals were investigated in steady-state condition and then under-time varying conditions respectively in [30] and [31] to overcome the compensating effect of the control system on current harmonics to diagnose rotor faults.

The measured direct and quadrature current components were proposed in [32] and [33] respectively for the detection of rotor faults. In [34-35], an exhaustive investigation of the impact of the control strategy and even the tuning of the speed regulator was considered as potential criteria for the selection of the appropriate motor fault diagnosis technique. Virtual magnetizing current is proposed in [36] to detect and quantify rotor broken bars in induction motors.

In general, when faults occur in the machine, the typical current fault-harmonics might become less visible due to the compensating action of the control system. Therefore, the relevance of the typical fault components issued from MVSA could be affected by the bandwidth of current regulators. For this reason, the sensitivity of the MVSA is investigated in respect to the bandwidth variations for double cage induction motor broken bars. Experimental results show clearly that this impact is not negligible, and the diagnostic procedure based on MVSA in closed-loop operating conditions must be considered in order to perform an effective rotor broken bars detection.

\section{Rotor FAUlt FreQuencies Propagation}

Like any other rotating electrical machine, the double cage induction motor is subjected to electromagnetic and mechanical forces symmetrically repartitioned. In healthy conditions only the fundamental frequency $f$ exists in stator currents ( $f$ : supply frequency).

If the rotor part is damaged, the rotor symmetry of the machine is lost producing a reverse rotating magnetic field related to an inverse sequence component at frequency $-s f$. This inverse sequence is reflected on the stator side, producing the frequency $(1-2 s) f$. These frequency components generate electromagnetic and mechanical interactions between stator and rotor parts. Consequently torque and speed ripple effects are generated at frequency $2 s f$, which modulate the rotating magnetic flux [36].

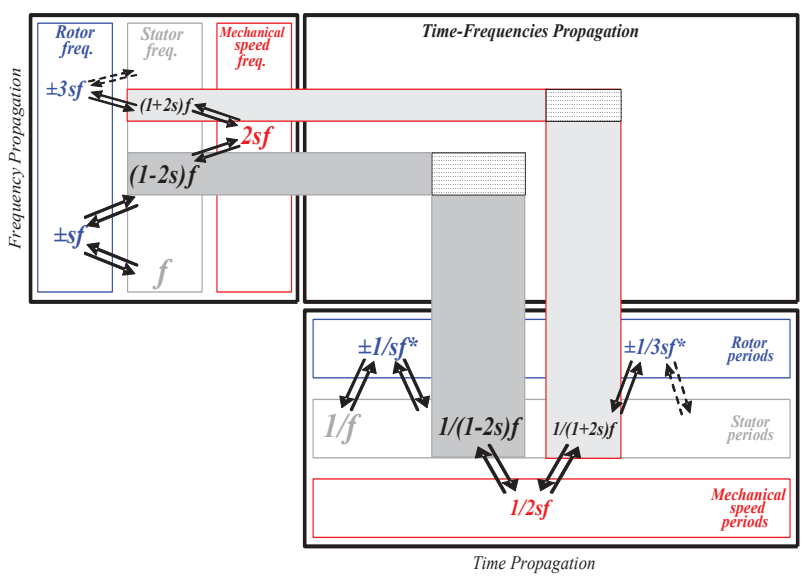

Fig. 1. Block diagram of the control scheme for a typical indirect fieldoriented control induction motor drive.

This modulation produces two current components, i.e., an additional left-side component at $(1-2 s) f$ and a right side component at $(1+2 s) f$. Following this interaction process, the frequency content of the stator currents show series of fault components at the following frequencies chain:

$$
f_{k r}^{i_{s}}=((1 \pm 2 k s) f)_{k=1,2,3, \ldots}
$$


More specifically, for large or double squirrel-cage motors, as long as the contact impedance between the rotor bars and iron core is small or the copper bars are directly inserted into the laminated iron slots, the broken bar is no longer a physical condition ensuring an open circuit and inters bars or cross-path currents can flow. As a consequence, these inter bar transverse currents interact with the radial stator flux density, generating axial forces. These facts lead mainly to the presence of two chains of fault components:

$$
\begin{gathered}
f_{k r}^{v i{ }_{-}{ }^{1}}=\left(f_{\text {mec }} \pm 2 k s f\right)_{k=1,2,3, \ldots} \\
f_{k r}^{v i{ }_{-}{ }^{2}}=((6-2 k s) f)_{k=1,2,3, \ldots}
\end{gathered}
$$

both in radial and axial vibration directions $\left(f_{\text {mec }}\right.$ denotes the mechanical speed of the motor) [30]. In next sections, the focus will be exclusively on tracking the detectability of the most relevant fault component $\left(f_{m e c}-2 s f\right)$ of the harmonic chain $\left(f_{m e c} \pm 2 k s f\right)_{k=1,2,3, \ldots}$ in frequency domain, in presence of the control damping effect.

\section{IMPLEMENTED CONTROL STRATEGY: EXPERIMENTAL SETUP}

Indirect rotor field oriented control is one of the most widely used control strategy for induction motor drives in industrial applications. In the following, a description of the investigated control strategy, and its experimental implementation supplying a double cage induction motor under healthy and rotor broken bars.

\section{A. Control Strategy Description}

As illustrated by the block scheme in Fig. 2, the double cage induction motor control system is based on two cascaded loops. The outer loop is dedicated to the speed control. Whereas the inner one is related to the control of the direct and quadrature stator current components. The blocks containing $D$ and $D-1$ represent respectively the Clarke's and the inverse Clarke's transformations from a three phase to a two phase d-q system.

A classical PI regulator is used to generate the reference value of the torque, which produce the current component $\mathbf{i}_{\mathrm{qs}} *$. The two other PI regulators are dedicated to the control of the $d-q$ components of the stator current. Since the control symmetry of the $d$ - $q$ current components, as illustrated by Fig. 3, the PI regulators have the same parameters for the $d$-axis and the $q$-axis loops.

Considering a perfect decoupling of the two axis, the direct and quadrature $\mathbf{v}_{\mathrm{sd}}{ }^{*}$ and $\mathbf{v}_{\mathrm{sq}}{ }^{*}$ voltage equations are:

$$
\begin{aligned}
& \mathbf{v}_{s d}^{*}=R_{s} \mathbf{i}_{s d}+\sigma L_{s} \frac{d}{d t} \mathbf{i}_{s d} \\
& \mathbf{v}_{s q}^{*}=R_{s} \mathbf{i}_{s q}+\sigma L_{s} \frac{d}{d t} \mathbf{i}_{s q}
\end{aligned}
$$

where $R_{s}$ is the stator resistance, $L_{s}$ is the stator inductance, and $\sigma$ is the leakage coefficient. Using a zero pole cancellation and considering for the PI regulator the following transfer function:

$$
P I(s)=K_{p}+\frac{K_{i}}{s}
$$

The parameters of the regulators can be derived as follows:

$$
\begin{gathered}
K_{p}=2 \pi B_{p i} \sigma L_{s} \\
K_{i}=2 \pi B_{p i} R_{s}
\end{gathered}
$$

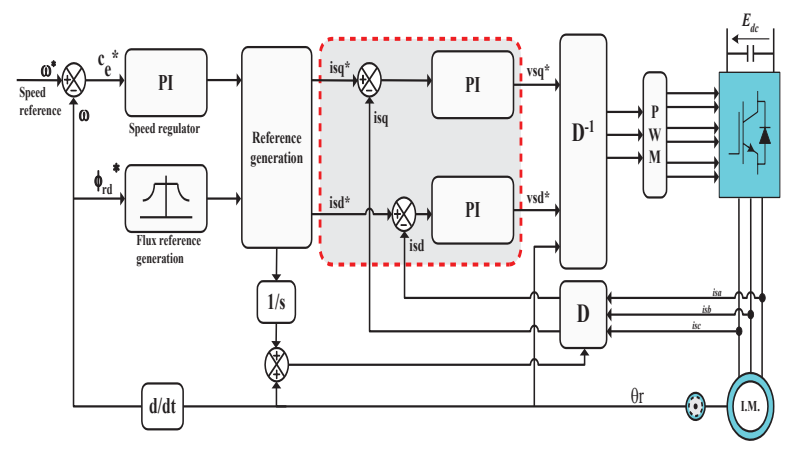

(a)

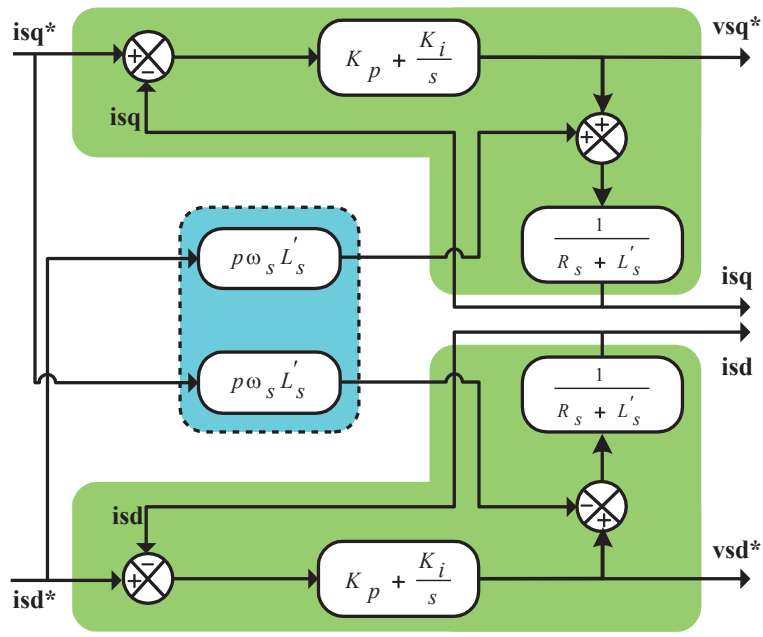

(b)

Fig. 2. Block diagram of a typical indirect field-oriented control induction motor drive; (a) Implemented IRFOC drive; (b) current control loops for PI controller design.

Being $B_{p i}$ the bandwidth of stator current closed-loop. In the next sections, the impact of the above bandwidth on rotor bar breakage detectability based on axial and radial vibration analysis will be evidenced.

\section{B. Experimental Setup Description}

A complete set of experimental tests have been carried out. Fig. 3 shows details of the experimental testbed. For this purpose, two double cage induction motors are available; one healthy, and the second with a drilled broken bar (the bar was completely disconnected from the common end-ring). Photos of the used healthy and faulty double cage rotors are shown in Fig. 3.

The characteristics of the double cage induction motors used for experiments are presented in Table I. A PWM-VSI converter is used to control the motor. A dSPACE system based on the DS1103 control board has been used to implement the indirect rotor field oriented control shown in Fig. 2. Two piezoelectric accelerometers Brüel \& Kjær model 4507 B 005, were mounted for measuring axial and radial vibrations of the core motors.

A NEXUS 2693 model as signal conditioner is used 
for vibration signals. The control board is also used for data acquisition and data processing. The experimental tests have been performed by operating the machine under full load operating conditions.

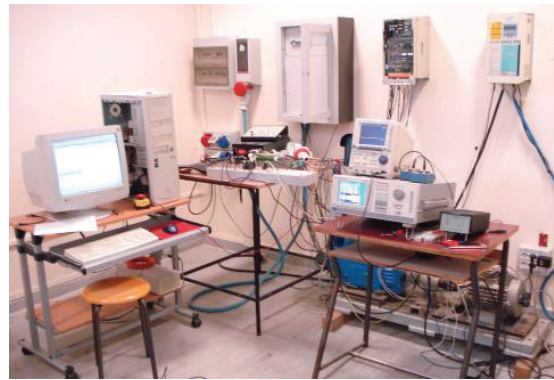

(a)

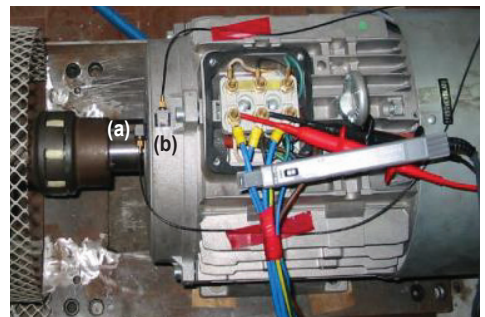

(b)

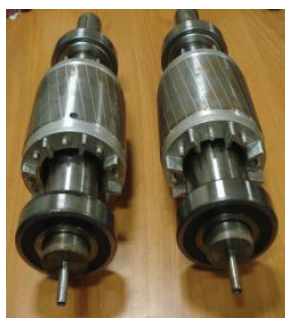

(c)
Fig. 3. Experimental Test-bench details ;(b) accelerometer positions, and the current probe; (c) healthy and drilled rotor bar.

TABLE I

INDUCTION MOTOR PARAMETERS

\begin{tabular}{|l|r|r|}
\hline Data & \multicolumn{2}{|c|}{ Value } \\
\hline Rated Power & $\mathrm{kW}$ & 5.5 \\
\hline Rated stator voltage & $\mathrm{V}$ & 400 \\
\hline Rated current & $\mathrm{A}$ & 13 \\
\hline Rated frequency & $\mathrm{Hz}$ & 50 \\
\hline Rated speed & $\mathrm{rpm}$ & 2870 \\
\hline Rotor diameter & $\mathrm{mm}$ & 110 \\
\hline Axial length of the rotor & $\mathrm{mm}$ & 90 \\
\hline Air gap length & $\mathrm{mm}$ & 0.5 \\
\hline
\end{tabular}

\section{Rotor BAR BREAKAGE DETECTION: CONTROL IMPACT ON MVSA}

In this section, the detectability of rotor bar breakage using MVSA, is presented and discussed. Fig. 4. shows the MAVSA spectra issued from experimental results, under healthy and rotor bar breakage. The magnitudes are normalized to the maximum amplitude of the harmonic component at frequency $6 f$. The spectrum under healthy machine is considered as reference in comparison to the faulty case.

Axial vibration signal spectra close to the mechanical frequency $f_{\text {mec }}$ are depicted in Fig. 4 for full load opearating conditions; under healthy (Red) and rotor bar breakage (Blue). As it can be seen, under faulty condition the left side component $\left(f_{m e c}-2 s f\right)$ increases in a significant way in comparison to the healthy case. More specifically, the left side component $\left(f_{m e c}-2 s f\right)$ shows a significant increase from $-41,25 \mathrm{~dB}$ under healthy condition, to $-32,36 \mathrm{~dB}$ for the bar breakage motor.

Let us now focus on the contribution of the fault component $\left(f_{m e c}-2 s f\right)$ issued from radial vibration analysis. MRVSA. Radial vibration signal spectra close to the mechanical frequency $f_{\text {mec }}$ are depicted in Fig. 5 for the same above full load opearating conditions; under healthy (Red) and rotor bar breakage (Blue). As it can be seen, under faulty condition the left side component $\left(f_{m e c}-2 s f\right)$ increases in a significant way in comparison to the healthy case. More specifically, the left side component $\left(f_{m e c}-2 s f\right)$ shows an increase from $-42,03 \mathrm{~dB}$ under healthy condition, to $-33,20 \mathrm{~dB}$ for the bar breakage motor.

By comparing the contribution of the fault component $\left(f_{\text {mec }}-2 s f\right)$ issued from MAVSA and MRVSA, under healthy and faulty conditions, it is obvious that the relevance of this component is more important from axial than from radial vibration signals. This result is expected, according to the previous investigations [27,28], where the contribution of the fault component $\left(f_{m e c}-2 s f\right)$ from MAVSA and MRVSA, was investigated in line-fed conditions, under healthy and bar breakage conditions. Once again, the axial vibration analysis is a reliable technique for the detection of rotor bar breakage in double squirrel cage induction motors integrated in closed-loop system. But it is worth noting that the variation in magnitudes is considerably reduced under closed-loop operating conditions when compared to the line-fed operating conditions.

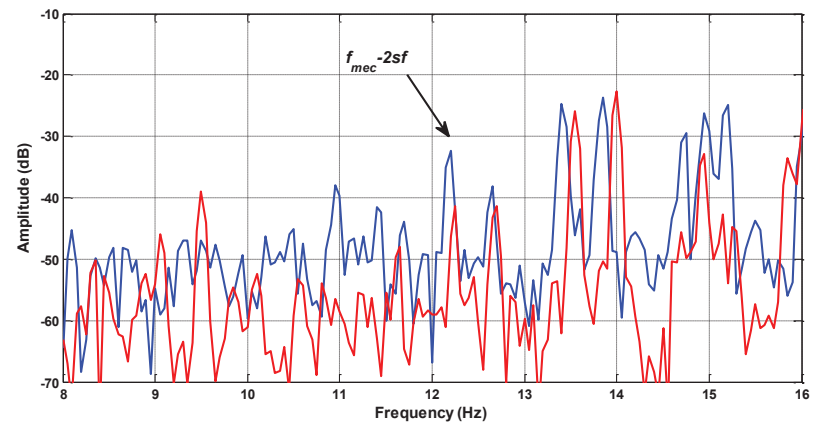

Fig. 4. Axial vibration spectra at full load operating conditions; healthy (Red), and rotor bar breakage (Blue).

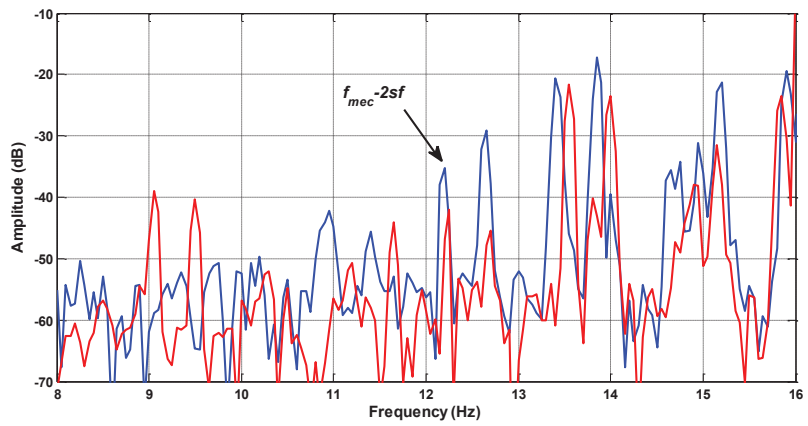

Fig. 5. Radial vibration spectra at full load operating conditions; healthy (Red), and rotor bar breakage (Blue).

In order to evaluate the impact of the control closedloop bandwidth impact, different experimental tests were performed with different values for the current PI controllers parameters, corresponding to different closedloop bandwidth starting from $200 \mathrm{~Hz}$ to $70 \mathrm{~Hz}$. In Fig. 6, the experimental results, issued from MAVSA, for rotor bar breakage condition, and under different bandwidth controller parameters are presented. It is evident that the contribution, of the fault component of interest, is 
damped by the action of the control system. Observing the zoomed view of the magnitude fault component, it is clear that the lower magnitude is registered for the largest bandwidth current PI controllers $(200 \mathrm{~Hz})$. On the other hand, similar analysis based on radial vibration analysis was performed. In Fig. 7, the experimental results, issued from MRVSA, for rotor bar breakage condition, and under the same different bandwidth controller parameters are presented. The contribution, of the fault component of interest, is damped by the action of the control system. The same observations noticed for the axial vibration signature analysis are valid also for MRVSA.

Observing the zoomed views presented in Fig. 6 and Fig. 7 corresponding to MAVSA and MRVSA respectively, it can be seen that the control impact, on rotor bar breakage sensitivity, is more important on MRVSA than MAVSA.

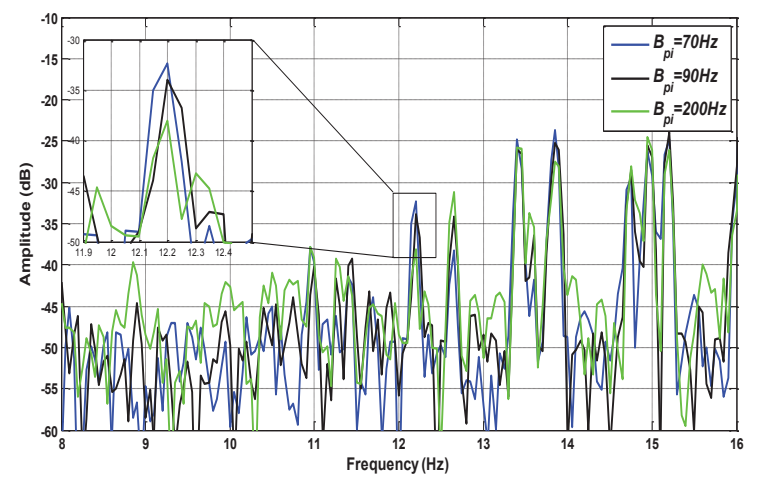

Fig. 6. Axial vibration spectra at full load operating conditions; bandwidth impact on the $\left(f_{m e c}-2 s f\right)$ component under rotor bar breakage.

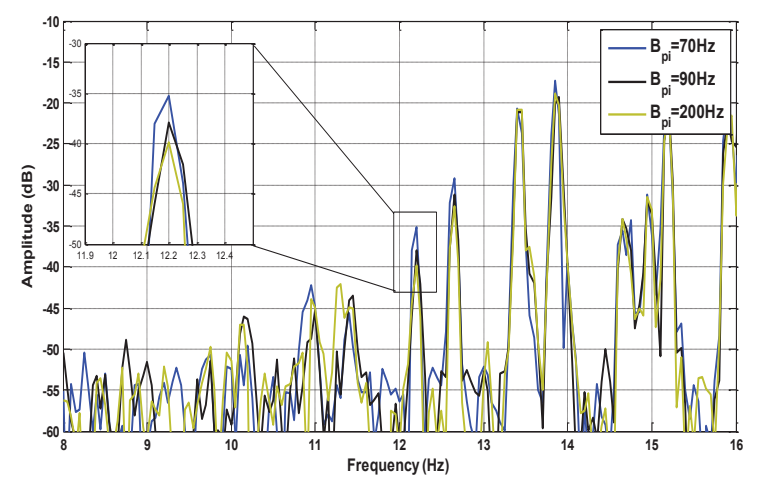

Fig. 7. Radial vibration spectra at full load operating conditions; bandwidth impact on the $\left(f_{m e c}-2 s f\right)$ component under rotor bar breakage.

\section{CONCLUSION}

The classical motor current signature analysis technique may fail due to the presence of inter bar currents, which reduce the amplitude of the tracked fault components in frequency domain. Vibration analysis may not only detect the existence of inter bar currents under broken bar failure, but also enhance the detectability of this type of fault by considering classical signal processing techniques. For small induction motors, the MCSA diagnostic procedure is still effective. But, with high power or double cage motor, like the tested one, the combined use of current and vibration analysis is recommended in order to avoid erroneous diagnosis. As proved in previous contributions [27,28], the signature issued from axial vibration analysis is more relevant, in comparison to the current and radial vibration analysis results in line-fed induction motors. In this paper, the robustness of the fault signature issued from axial vibrations in closed-loop operation, in comparison to the radial vibration one, is evidenced. Effectively, due to the important relevance of the fault component issued from axial vibration, this issue makes the detectability less sensitive to the control parameters. Tracking these fault components in Time-Frequency domain is our main challenge in the future to guaranty a reliable rotor broken bar fault signature in a double cage induction motor in closed-loop operating conditions.

\section{ACKNOWLEDGMENT}

This work was realized with the contribution of SDES Laboratory - UNINETLAB - University of Palermo.

\section{REFERENCES}

[1] V. Boscaino, P. Livreri, F. Marino, and M. Minieri , "Linear-non-linear Digital Control for DC-DC Converters with Fast Transient Response", ACTAPRESS, International Journal of Power and Energy Sources, 2009, vol. 29, pp.38-47. Doi: 10.2316/Journal.203.2009.1.203-4021.

[2] G.M. Di Blasi, V. Boscaino, P. Livreri, F. Marino, and M. Minieri, "A Novel Linear-Non-Linear Digital Control for DC/DC Converter with Fast Transient Response", IEEE Applied Power Electronics Conference, APEC2006, USA 2006. pp. 705-711. DOI: 10.1109/APEC.2006.1620616.

[3] V. Boscaino, M. Gaeta, G. Capponi, F. Marino, "Nonlinear digital control improving transient response: Design and test on a multiphase VRM," Symposium on Power Electronics Electrical Drives Automation and Motion (SPEEDAM), 14-16 June, 2010, pp.507-512

[4] V. Boscaino, P. Livreri, F. Marino, and M. Minieri, "Current-Sensing Technique for Current-Mode Controlled Voltage Regulator Modules". Microelectronics Journal, Elsevier, vol.39, no.12, Dec. 2008, pp.1852-1859.

[5] V. Boscaino and G. Capponi, "A High-Efficiency, LowCost Solution for On-Board Power Converters", Advances in Power Electronics, Hyndawi, vol. 2012, pp. 1-12. doi:10.1155/2012/259756, Sept. 2012.

[6] A. Dannier, R. Rizzo: "An overview of Power Electronic Transformer: Control strategies and topologies", Symposium on Power Electronics, Electrical Drives, Automation and Motion SPEEDAM 2012, Sorrento, June 20-22, 2012, pp. 1552-1557.

[7] L. Piegari, R. Rizzo, P. Tricoli: "A Comparison between Line-Start Synchronous Machines and Induction Machines in Distributed Generation", Prezglad Elektrotechniczny (Electrical Review), Vol. 88 n. 5b, 2012, pp. 187-193.

[8] V. Boscaino, G. Capponi, and F. Marino, "Experimental test on a fuel cell-supercapacitor hybrid power supply for a digital still camera" IEEE Universities Power Engineering Conference, UPEC'09, Scotland, 2009, pp.1-5.

[9] V. Boscaino, G. Capponi, P.Livreri, and F. Marino, "Fuel Cell Modelling for Power Supply Systems Design”. IEEE International Workshop on Control and Modeling for Power Electronics, COMPEL'08, Zurich, 2008. pp.1-5. 
[10] V.Boscaino, R. Miceli, G. Capponi,D. Casadei "Fuel cell Modelling and Test:experimental validation of model accuracy," 4th IEEE International Conference on Power Engineering,Energy and Electrical Drives 2013, POWERENG 2013, May 2013, Turkey. pp. 1-6.

[11] C. Spataro: "ADC Based Measurements: a Common Basis for the Uncertainty Estimation", Proc. of 17th IMEKO TC4 Symposium. Kosice, Slovakia. Sept. 08-10, 2010.

[12] R. Candela, V. Di Dio, E. Riva Sanseverino, and P. Romano, "Reconfiguration techniques of partial shaded PV systems for the maximization of electrical energy production," International Conference on Clean Electrical Power, ICCEP '07, 2007, pp. 716-719.

[13] G. Cipriani, V. Di Dio, D. La Cascia, R. Miceli, and R. Rizzo, "A novel approach for parameters determination in four lumped PV parametric model with operative range evaluations," International Review of Electrical Engineering (I.R.E.E.), vol. 8, Apr. 2013.

[14] V. Di Dio, R. Miceli, C. Rando, and G. Zizzo, "Dynamics photovoltaic generators: Technical aspects and economical valuation," Symposium on Power Electronics Electrical Drives Automation and Motion SPEEDAM, 2010, pp. 635-640.

[15] Di Tommaso A O, Genduso F, Miceli R, Ricco Galluzzo G. "Computer Aided Optimization Via Simulation Tools of Energy Generation Systems With Universal Small Wind Turbines". IEEE International Symposium on Power Electronics for Distributed Generation Systems (PEDG) 2012. Aalborg, Denmark, June 25-28 2012, p. 570-577.

[16] Cecati C., Genduso F., Miceli, R., Ricco Galluzzo G., “A suitable control technique for fault-tolerant converters in distributed Generation",IEEE International Symposium on Industrial Electronics ISIE 2011, Gdansk, 27-30 June 2011, pp. 107-112.ISBN: 978-142449312-8.

[17] H. A. Toliyat, S. Nandi, S. Choi, and H. Meshgin-Kelk, Electric Machines, Modeling, condition monitoring and Fault diagnosis. CRC Press, 2012.

[18] V. Di Dio, G. Cipriani, R. Miceli, R. Rizzo, "Design criteria of tubular linear induction motors and generators: a prototype realization and its characterization," Leonardo Electronic Journal of Practices and Technologies, vol. 12, 2013.

[19] A.H. Bonnett, C. Yung, "Increased Efficiency Versus Increased Reliability", IEEE Industry Applications Magazine, Vol. 14, Issue 1, Jan./Feb. 2008.

[20] F. Filippetti, A. Bellini, G. A. Capolino, " Condition Monitoring and Diagnosis of Rotor Faults in Induction Machines: State of Art and Future Perspectives", IEEEWorkshop on electrical machines, design, control and diagnosis IEEE-WEMDCD '13, Paris, 11-12 March 2013.

[21] J. Mroz, "Temperature field of a double squirrel-cage motor during startup," Electric Power Applications, IEE Proceedings -, vol. 152, no. 6, pp. 1531 - 1538, nov. 2005.

[22] R. S. Weiser, C. Kral, and F. Pirker, "The Vienna induction machine monitoring method; on the impact of the field oriented control structure on real operational behavior of a faulty machine," IECON, 1998, vol. 3, pp. 1544-1549.

[23] A. Ceban, R. Pusca, and R. Romary, "Study of rotor faults in induction motors using external magnetic field analysis," IEEE Transactions on Industrial Electronics, vol. 59, no. 5, pp. 2082 -2093, may 2012.

[24] A. Yazidi, H. Henao, G. A. Capolino, M. Artioli, F. Filippetti, and D. Casadei, "Flux signature analysis: An alternative method for the fault diagnosis of induction machines," IEEE PowerTech, St. Petersburg, Russia, Jun. 2005, Paper n 424, CD-ROM.

[25] C. Concari, G. Franceschini, and C. Tassoni, "Differential Diagnosis Based on Multivariable Monitoring to Assess Induction Machine Rotor Conditions", IEEE Trans. on Industrial Electronics, vol. 55, no. 12, Dec. 2008.

[26] R.F. Walliser, C.F.Landy, "Assessment of interbar currents in double cage induction motors with broken bars," IEEE Trans. Energy Conv., vol.9, n.1, pp.159-164, March 1994.

[27] A.O. Di Tommaso, R. Miceli, G. Ricco Galluzzo, "Monitoring and Diagnosis of Failures in Squirrel-Cage Induction Motors Due to Cracked or Broken Bar", IEEESDEMPED'2011, Bologna, 2011, pp. 39-44.

[28] Y. Gritli, A.O. Di Tommaso, F. Filippetti, R. Miceli, C. Rossi, "Investigation of Motor Current Signature and Vibration Analysis for Diagnosing Rotor Broken Bars in Double Cage Induction Motors", Symposium on Power Electronics, Electrical Drives, Automation and Motion, SPEEDAM‘2012, June 14-16, Pisa (Italy), pp. 1360-1365.

[29] J. J. Rangel-Magdaleno, R. J. Romero-Troncoso, R. A. Osornio-Rios, E. Cabal-Yepez, L. M. Contreras-Medina, "Novel Methodology for Online Half-Broken-Bar Detection on Induction Motors", IEEE Trans. on Inst. and Meas., vol. 58, no. 5, May. 2009.

[30] A. Stefani, A. Yazidi, C. Rossi, F. Filippetti, D. Casadei, G.A. Capolino, "Doubly fed induction machines diagnosis based on signature analysis of rotor modulating signals," IEEE Transactions on Industry Applications, vol. 44, no. 6, pp. 1711-1721, Nov./Dec. 2008.

[31] Y. Gritli, L. Zarri, C. Rossi, F. Filippetti, G. Capolino, and D. Casadei, "Advanced diagnosis of electrical faults in wound rotor induction machines," IEEE Trans. on Industrial Electronics (Accepted for publication), 2012.

[32] A. Bellini, F. Filippetti, G. Franceschini, and C. Tassoni, "Closed-loop control impact on the diagnosis of induction motors faults," IEEE Trans. on Industry Applications, vol. 36, no. 5, pp. 1318-1329, Sep./Oct. 2000.

[33] E. Serna, and J. M. Pacas, "Detection of rotor faults in field oriented controlled induction machines", IEEE IAS Annual Meeting, Tampa, FL, USA, pp. 1-7, October 8-12, 2006.

[34] S. M. A. Cruz and A. J. M. Cardoso, "Diagnosis of rotor faults in closed-loop induction motor drives," IEEE IAS Annu. Meeting, Tampa, FL, 2006, pp. 2346-2353.

[35] S.M A. Cruz, A. J. M. Cardoso, "Analysis and diagnosis of rotor faults in high-performance induction motor drives," Proc. Int. Conf. Elect. Mach., Greece, 2006, pp. 1-6.

[36] S. M. A. Cruz, A. Stefani, F. Filippetti ,A. J. M. Cardoso, "A New Model-Based Technique for the Diagnosis of Rotor Faults in RFOC Induction Motor Drives", IEEE Trans. on Industrial Electronics, vol. 55, no. 12, Dec. 2008, pp. 4218-4228. 